\title{
Knowledge, attitude and perceptions of mothers with children under five years of age about vaccination in Mangalore, India
}

\author{
Soundarya Mahalingam¹, Abhijna Soori ${ }^{2}$, Pradhum Ram², Basavaprabhu Achappa ${ }^{3}$, Mukta Chowta ${ }^{4}$, \\ Deepak Madi $^{3}$
}

${ }^{1}$ Associate Professor, Paediatrics, Kasturba Medical College, Mangalore, Affiliate to Manipal University, ${ }^{2}$ Final Year MBBS Student, Kasturba Medical College, Mangalore, Affiliate to Manipal University, ${ }^{3}$ Associate Professor, Internal Medicine, Kasturba Medical College, Mangalore, Affiliate to Manipal University, ${ }^{4}$ Additional Professor, Pharmacology, Kasturba Medical College, Mangalore, Affiliate to Manipal University

\section{A B S TR A C T}

Objective: Vaccination is a cost-effective intervention to prevent major illnesses that contribute to child mortality in the country. Increase in parental knowledge about vaccination will lead to increase in vaccination rates of children The main aim of our study was to assess the Knowledge (K), attitudes (A) and perceptions (KAP) of mothers with children under five years of age about vaccination. We also compared the KAP data between urban and rural setup. Methodology: This cross sectional descriptive study was conducted on mothers attending the Urban Health Centre (in Mangalore city) and on mothers attending a Peripheral Health Centre (Bengre, outskirts of Mangalore) havingchildren under five years of ageA semi structured pre validated questionnaire designed to assess the Knowledge, Attitudes and Perceptions about vaccination was administered to mothers attending the Urban Health Centre and on mothers attending a Peripheral Health Centre havingchildren under five years of age. Results: Among the study participants, 74 were from urban setup and 126 from rural set up. Around $8(10.8 \%)$ from urban area and $78(61.9 \%)$ from rural area were illiterate. Mothers were the main decision makers regarding vaccination of the child in both urban and rural setup. The main source of information regarding vaccination differed among urban and rural setup, being the hospital and the anganwadi worker respectively. There was a statistically significant difference between urban and rural mothers when it was asked whether they knew why vaccination was important. A majority of the mothers both in the urban and rural areas believed that vaccines were safe. Among the urban mothers $90.5 \%$ and $62.7 \%$ of mother from rural were able to identify polio as a vaccine preventable disease.On a net analysis, 64(86.5\%) mothers in the urban area and only $64(50.8 \%)$ mothers in the rural areamothers found to have favourable knowledge, attitudes, perceptions and practices towards vaccination. Conclusion: A significant number of mothers in rural areas were unaware about the vaccination and its implications. Even in the urban areas we found significant lacunae in the KAP of mothers towards childhood vaccination.

Key words: Knowledge, Attitude, Perception, Vaccine
Access this article online Website:

http://nepjol.info/index.php/AJMS

\section{INTRODUCTION}

Vaccination is one of the most cost-effective interventions to prevent major illnesses that contribute to child mortality in the country, particularly in environments where malnourished children, overcrowding, poverty and illiteracy reign. Knowledge (K), positive attitudes (A) and appropriate perceptions $(\mathrm{P})$ about vaccination hence become one of the main tools to reduce the incidence of vaccine preventable diseases (VPDs) thus reducing childhood mortality and morbidity. In our society, a large chunk of the population lives in rural areas, where mothers are illiterate and have numerous myths about vaccination; this results in children being unimmunized and susceptible and hence causes a serious policy concern. Evidence about the inequalities in vaccination practices exist even though 
childhood immunization has been an important part of maternal and child health services since the 1940s. ${ }^{1}$

In 2010 it was estimated that 1.7 million children died from vaccine preventable diseases. ${ }^{2}$ It was also noted that 19.3 million children had been incompletely vaccinated, leaving them susceptible to vaccine preventable disease mortality and morbidity. Approximately $50 \%$ of all under vaccinated children live in three countries, India being one of them. ${ }^{3}$

The situation of under immunization is not only in the rural areas of the country, but also in urban areas as the migration of workersand the mushrooming of slums in urban areas are occurring at a rapid rate, and these are areas with unprecedented poverty, illiteracy, overcrowding and disease. ${ }^{4}$ National Family Health Survey-3 reports that only $43.5 \%$ of children in India receive all of their primary vaccines by 12 months of age. ${ }^{5}$ Main reasons identified for poor coverage includes inadequacy of community participation in routine immunization and Information Education and Communication activities. ${ }^{6}$ Negative parental perceptions of vaccination are also an important barrier to childhood vaccination. ${ }^{7}$ Therefore it is important to understand the variables that influence parental decisions to vaccinate their children and plan measures to overcome these barriers. A way to measure these variables, beliefs and behaviour of parents is to conduct a Knowledge, Attitudes and Perceptions (KAP) study. With this outlook, this study was planned to assess the KAP of mothers with children under five years of age about vaccination and to compare the KAP data between urban and rural setup.

\section{METHODOLOGY}

This cross sectional descriptive study was conducted on mothers attending the Urban Health Centre (in Mangalore city) and on mothers attending a Peripheral Health Centre (Bengre, outskirts of Mangalore) havingchildren under five years of age. The sample population is representative of the mothers of both these areas. The study was conducted after obtaining the ethics committee approval from Institutional Ethics committee. Informed consent was obtained from all eligible participants after explaining the objectives and nature of this study in their own language.

A semi structured pre validated questionnaire designed to assess the Knowledge, Attitudes and Perceptions about vaccination was administered to all the mothers fulfilling the above criteria. The data collected through this questionnaire includes: mother's age, educational status, occupation and socioeconomic status, number of children in the family, place of delivery and place of vaccination, immunization status of their child/children, knowledge of vaccines and the diseases they prevent, age of vaccine administration, distance of the health facility from home andtravel time, the source of the information regarding vaccination and the parental attitude towards vaccination. Confidentiality was maintained in the study.

\section{Statistical analysis}

Data was analyzed using SPSS version 11.0. Categorical variable were analyzed using chi-square test. A pvalue less than 0.05 was considered as statistically significant.

\section{RESULTS}

Among the study participants, 74 were from urban setup and 126 from rural set up. Table 1 shows the demographic characteristics of the participants. Around $8(10.8 \%)$ from urban area and $78(61.9 \%)$ from rural area are illiterate, the difference being statistically very significant $(p<0.0001)$. Seventeen $(24.4 \%)$ of the participants from urban set up and $47(37.3 \%)$ from rural set up were employed, the difference being statistically significant $(\mathrm{p}=0.04)$.

Mothers were the main decision makers regarding vaccination of the child in both urban and rural setup. The main source of information regarding vaccination differedamong urban and rural setup, being the hospital and the anganwadi worker respectively (Table 1).

When the awareness regarding vaccination was assessed, it was found that all mothers from the urban area were aware about childhood vaccination while $6.4 \%$ of the rural mothers were unaware about childhood vaccination and this difference was found to be statistically significant $(\mathrm{p}=0.027)$.

Table 2 shows the comparison of knowledge about vaccination among mothers from urban and rural area. There was a statistically significant difference between urban and rural mothers when it was asked whether they knew why vaccination was important. Urban mothers showed a significantly higher knowledge in this $\operatorname{regard}(75.6 \%)$ as against $62.69 \%$ in rural mothers. Around $91.89 \%$ of the mothers in the urban setup knew when vaccination was to be initiated as against $44.44 \%$ in the rural setup, implying that a statistically significant number of the mothers in the rural areas did not know when to initiate vaccination $(55.56 \%)$.

When other knowledge regarding vaccine safety and situations of vaccine administration were analysed; a majority of the mothers both in the urban and rural areas believed that vaccines were safe. A large percentage 35\% 
in the rural population of mothers did not know whether vaccinations were safe for their children which underlies the problem of illiteracy in the mothers. Most of the mothers (54\% urban and 33.3\% rural) would not vaccinate their child if child was having mild upper respiratory tract infection and (63.5\% urban and $43.7 \%$ rural) would not vaccinate their child if child had fever.

\begin{tabular}{|c|c|c|c|c|}
\hline \multirow[t]{2}{*}{ Characteristics } & \multicolumn{2}{|c|}{ Urban } & \multicolumn{2}{|r|}{ Rural } \\
\hline & $\begin{array}{c}\text { Number } \\
\text { (74) }\end{array}$ & Percentage & $\begin{array}{l}\text { Number } \\
(126)\end{array}$ & Percentage \\
\hline \multicolumn{5}{|l|}{ Education } \\
\hline Illiterate & 8 & $10.8 \%$ & 78 & $61.9 \%$ \\
\hline School & 32 & $43.2 \%$ & 36 & $30.2 \%$ \\
\hline Pre degree & 24 & $32.4 \%$ & 9 & $7.1 \%$ \\
\hline Graduate & 10 & $13.5 \%$ & 3 & $2.4 \%$ \\
\hline \multicolumn{5}{|l|}{ Occupation } \\
\hline Housewife & 56 & $75.7 \%$ & 79 & $62.7 \%$ \\
\hline Govt employed & 2 & $2.7 \%$ & 2 & $1.6 \%$ \\
\hline Self Employed & 4 & $5.4 \%$ & 9 & $7.1 \%$ \\
\hline Housemaid & 1 & $1.4 \%$ & 18 & $14.3 \%$ \\
\hline Others & 10 & $13.5 \%$ & 18 & $14.3 \%$ \\
\hline \multicolumn{5}{|l|}{$\begin{array}{l}\text { Decision maker } \\
\text { (in matters of } \\
\text { immunization) }\end{array}$} \\
\hline Mother & 51 & $68.9 \%$ & 89 & $70.6 \%$ \\
\hline Father & 2 & $2.7 \%$ & 1 & $0.8 \%$ \\
\hline Both & 21 & $28.4 \%$ & 35 & $27.8 \%$ \\
\hline \multicolumn{5}{|l|}{$\begin{array}{l}\text { Sources of } \\
\text { information regarding } \\
\text { immunization }\end{array}$} \\
\hline $\begin{array}{l}\text { ANM (auxiliary } \\
\text { nurse midwife) }\end{array}$ & 8 & $10.8 \%$ & 18 & $14.3 \%$ \\
\hline TV/Radio & 15 & $20.3 \%$ & 11 & $8.7 \%$ \\
\hline Anganwadi worker & 16 & $21.6 \%$ & 54 & $42.9 \%$ \\
\hline Hospital & 73 & $98 \%$ & 35 & $27.8 \%$ \\
\hline Doctor & 40 & $54 \%$ & 16 & $12.7 \%$ \\
\hline
\end{tabular}

Figure 1 shows the vaccine preventable diseases identified by the urban and rural mothers. Among the urban mothers $90.5 \%$ and $62.7 \%$ of mother from rural were able to identify polio as a vaccine preventable disease. Similarly $39.2 \%$ of mothers in urban and $15.9 \%$ of mother in rural knew that tuberculosis is prevented by BCG vaccine. No mother could name all the diseases prevented by DPT vaccine. Around $47.3 \%$ of mothers from urban area and $69 \%$ of mothers from rural area had no knowledge about pertussis; $91.9 \%$ of mother from urban areas and $54 \%$ of mothers from rural area knew the disease prevented by OPV. Among urban mothers $86.5 \%$ and $54 \%$ of mothers from rural area knew the importance of attending pulse polio campaigns. Around $91.9 \%$ of urban mothers and $66.7 \%$ of rural mother knew that polio causes paralysis.

Around $25.7 \%$ of mothers from urban area had and $60.3 \%$ of mothers from rural set up had no knowledge about measles disease; $21.6 \%$ of urban mothers and $24.6 \%$ of rural mother felt thatthe most common side effect of

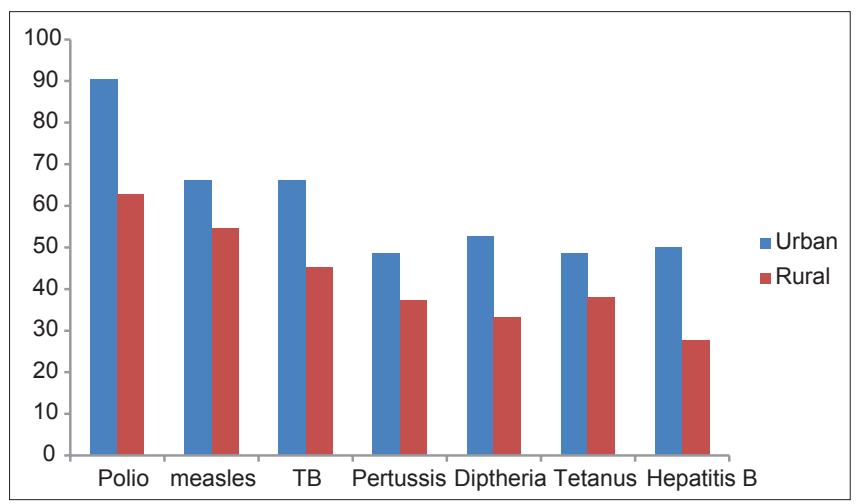

Figure 1: Vaccine Preventable Diseases identified by the urban and rural mothers

\begin{tabular}{|c|c|c|c|c|c|}
\hline \multirow[t]{2}{*}{ Survey questions } & \multicolumn{2}{|c|}{ Urban } & \multicolumn{2}{|c|}{ Rural } & \multirow[t]{2}{*}{$p$ value } \\
\hline & Number (74) & Percentage & Number (126) & Percentage & \\
\hline Mothers who knew the reason to vaccinate a child & 56 & $75.6 \%$ & 79 & $62.69 \%$ & $\mathrm{p}<0.041$ \\
\hline Mothers who did not know the reason for vaccination & 17 & $24.4 \%$ & 47 & $37.31 \%$ & \\
\hline Mothers who knew the correct age to start immunization & 68 & $91.89 \%$ & 56 & $44.44 \%$ & $p<0.0001$ \\
\hline Mothers who did not know the appropriate age to start vaccination & 6 & $8.1 \%$ & 70 & $55.56 \%$ & \\
\hline \multicolumn{6}{|l|}{ Are vaccines harmful? } \\
\hline No & 65 & $87.8 \%$ & 81 & $64.3 \%$ & \\
\hline Yes & 0 & - & 1 & $0.8 \%$ & \\
\hline Don’t Know & 9 & $12.2 \%$ & 44 & $34.9 \%$ & \\
\hline \multicolumn{6}{|l|}{ Can child with cold be vaccinated? } \\
\hline Yes & 21 & $28.4 \%$ & 40 & $31.8 \%$ & \\
\hline No & 40 & $54 \%$ & 42 & $33.3 \%$ & \\
\hline Don’t Know & 13 & $17.6 \%$ & 44 & $34.9 \%$ & \\
\hline \multicolumn{6}{|l|}{ Can child with fever be vaccinated? } \\
\hline Yes & 15 & $20.3 \%$ & 22 & $17.5 \%$ & \\
\hline No & 47 & $63.5 \%$ & 55 & $43.7 \%$ & \\
\hline Don't Know & 12 & $16.2 \%$ & 49 & $38.8 \%$ & \\
\hline
\end{tabular}


measles vaccine is allergic reaction. Around $32 \%$ of mother from urban and $17.4 \%$ of mother from rural area could name all diseases prevented by MMR vaccine. Only 4 of the 74 urban mothers and 12 of the 126 rural mothers have heard about complications after vaccination; the complications they listed were paralysis (8), deafness (3) and death (1).

Table 3 shows the comparison of attitude towards vaccination among urban and rural mothers. On analysing the attitude of the mothers towards vaccination, $89.2 \%$ of the mothers in the urban area and $55.6 \%$ of rural mothers felt vaccination were important and $45.4 \%$ of them in the rural area felt that vaccination was not required which was found to be statistically significant. Similarly when asked whether it was important to follow and complete the schedule $14.9 \%$ of urban mothers and $61.1 \%$ of rural mothers felt it was not needed to stick to a schedule or did not know. This also showed a high statistical significance and further underlines the cause of under immunization and poor vaccination coverage in our country. Most mothers in the urban area preferred to go a private health facility for vaccination $(65 \%)$ while $91 \%$ of rural mothers preferred the government health facilities. Around $96 \%$ of urban mothers and $90.5 \%$ of rural mothers were satisfied about how the vaccination and its information was provided.

Table 4 shows the comparison of practice of mothers regarding vaccination between urban and rural setup. On analyzing the perceptions and practices of the mothers regarding vaccination, $95.9 \%$ of urban mothers and $73 \%$ of rural mothers had completely immunized their children whereas $27 \%$ in the rural mothers and only $4 \%$ of urban mothers had not completed vaccinating their child for age. This was found to be statistically significant. This again highlights the importance of educating the mother about the importance of completing their child's vaccination.

On further analysis of the practices, $77 \%$ of the urban mothers and $72 \%$ of rural mothers gave history of side effects in their children following vaccination. The most common side effects were fever $76 \%$ urban and $72 \%$

\begin{tabular}{|c|c|c|c|c|c|}
\hline \multirow[t]{2}{*}{ Survey questions } & \multicolumn{2}{|c|}{ Urban } & \multicolumn{2}{|c|}{ Rural } & \multirow[t]{2}{*}{$p$ value } \\
\hline & Number (74) & Percentage & Number (126) & Percentage & \\
\hline \multicolumn{6}{|c|}{ Do you think vaccination is important? } \\
\hline Yes & 66 & $89.2 \%$ & 70 & $55.6 \%$ & $p<0.0001$ \\
\hline No/don't know & 8 & $10.8 \%$ & 57 & $45.4 \%$ & \\
\hline \multicolumn{6}{|c|}{ Is it important to follow vaccination schedule? } \\
\hline Yes & 63 & $85.1 \%$ & 49 & $38.9 \%$ & $p<0.0001$ \\
\hline No/don't know & 11 & $14.9 \%$ & 77 & $61.1 \%$ & \\
\hline \multicolumn{6}{|c|}{ Where do you prefer to receive vaccination? } \\
\hline Govt institute & 26 & $35.1 \%$ & 115 & $91.27 \%$ & $p<0.0001$ \\
\hline Private facility & 48 & $64.9 \%$ & 11 & $0.08 \%$ & \\
\hline \multicolumn{6}{|c|}{ Are you satisfied with the way in which vaccination is provided? } \\
\hline Yes & 71 & $95.9 \%$ & 114 & $90.47 \%$ & $p<0.156$ \\
\hline No & 3 & $4.1 \%$ & 12 & $9.53 \%$ & \\
\hline
\end{tabular}

\begin{tabular}{|c|c|c|c|c|c|}
\hline \multirow[t]{2}{*}{ Survey questions } & \multicolumn{2}{|c|}{ Urban } & \multicolumn{2}{|c|}{ Rural } & \multirow[t]{2}{*}{$p$ value } \\
\hline & Number (74) & Percentage & Number (126) & Percentage & \\
\hline \multicolumn{6}{|c|}{ Was immunization completed according to schedule? } \\
\hline Yes & 71 & $95.9 \%$ & 92 & $73 \%$ & $p<0.0001$ \\
\hline No & 3 & $4.1 \%$ & 34 & $27 \%$ & \\
\hline \multicolumn{6}{|c|}{ Did side effects appear? } \\
\hline Yes & 57 & $77 \%$ & 91 & $72.2 \%$ & \\
\hline No & 17 & $23 \%$ & 35 & $27.8 \%$ & \\
\hline \multicolumn{6}{|c|}{ If yes, which were seen? } \\
\hline Fever & 56 & $75.7 \%$ & 92 & $73 \%$ & \\
\hline Pain and swelling & 10 & $13.5 \%$ & 6 & $4.8 \%$ & \\
\hline Rash & 5 & $6.8 \%$ & 7 & $5.6 \%$ & \\
\hline \multicolumn{6}{|c|}{$\begin{array}{l}\text { Did you inform the doctor/health care worker about } \\
\text { the side effect seen in your child? }\end{array}$} \\
\hline Yes & 67 & $90.5 \%$ & 90 & $71.4 \%$ & \\
\hline No & 7 & $9.5 \%$ & 36 & $28.57 \%$ & \\
\hline
\end{tabular}


rural), pain and swelling in $13.5 \%$ urban and $4.8 \%$ rural children and rash in approximately $6 \%$ in both urban and rural children. However, where $90.5 \%$ of the urban mothers had informed the doctor about the side effects, $28.5 \%$ of rural mothers did not inform the health care workers about these side effects.

On a net analysis, favourable knowledge, attitudes, perceptions and practices towards vaccination were found in 64(86.5\%) mothers in the urban area and only $64(50.8 \%)$ mothers in the rural area. This difference was found to be statistically significant $(p<0.001)$ and again shows that the vaccination coverage is incomplete in our rural areas and this is the reason for increase in incidence of VPDs and difficulty in eradication of VPDs.

\section{DISCUSSION}

Assessment of knowledge of mothers about immunization showed wide gap in the knowledge of urban and rural mothers. When the sociodemography was assessed, a low literacy level was found in the rural mothers. This was significant and needs to be addressed in order improve knowledge about vaccination strategies and its advantages, as most mothers are the primary caretakers and decision makers regarding vaccination in their families. Singh et al had reported in their study that mothers had fair knowledge regarding the need for immunization but had poor knowledge regarding VPDs. ${ }^{6}$ In a study by Kapoor et al it was found that awareness and knowledge about VPDs increases with education status of mothers. ${ }^{8}$ In a cross sectional study conducted by Siddiqui et al inperiurban Karachi significantly better vaccination status was found among children with both parents literate as compared to children with bothparents illiterate. ${ }^{9}$ Our study revealed that anganwadi workers were the main source of information in the rural areas and it is this population that needs to be adequately trained so that they can spread the awareness upto the doorstep of the population. This was in concordance with the study by Bholanath et al. ${ }^{4}$

Knowledge about vaccination was assessed and it was found that a significant difference was seen between urban and rural mothers regarding the importance of vaccination as well as the age of initiation and completion of vaccination schedule. These lacunae need to be filled in order to attain 100\% vaccination coverage in the country especially in the rural areas. Further into the knowledge about vaccination most mothers from both urban and rural areas believed vaccines were safe, however a large proportion of mothers both from urban and rural setting would delay vaccinating their child in the circumstances of simple childhood illnesses. These myths must be abolished and mothers must be assured regarding the safety of vaccines. Mothers' inability to name or identify diseases other than poliomyelitis indicates that health education should be emphasized to enhance knowledge about the complete programme. This was emphasized in many studies. ${ }^{8,10,11}$

Most mothers in the urban area preferred private setup vaccination services as against preference of government health facilities by rural mothers. Hamid et a ${ }^{10}$ too in their study have reported that rural mothers preferred and trusted Government health facilities. This was probably because of the expense that would be incurred in a private health facility which an urban mother can afford. This was also found to be statistically significant and can draw attention to a hypothesis that if private clinics were not storing the vaccines properly, the children thus vaccinated would be still susceptible; especially in vaccines where maintenance of the cold chain is vital (eg. polio vaccine).

The mothers' practices regarding vaccination is found to be better in the urban than in the rural area as $95.9 \%$ of children in urban areas and only $73 \%$ of children in rural areas are completelyvaccinated according to schedule. One of the reason for not being able to complete vaccination on schedule cited by the mother was lack of awareness; the others being sick child and forgetfulness. In the study done by Hamid et al, lack of awareness and sick child were some of the reasons for not completing vaccination on schedule..$^{10}$ This indicates that the mothers do not completely understand the importance of vaccinating the child as was seen in our study.

Our study has found a significant difference in mothers from urban and rural areas in terms of their knowledge, attitude and practices regarding vaccination. The mothers from the urban $(86.5 \%)$ set up were more aware and showed favourable attitude and practices regarding vaccination than their rural counterparts $(50.8 \%)$. This could be attributed to the betterliteracy status of the urban mothers. It must also be kept in mind that since the majority of the mothers are the main caregivers and informantsregarding immunization, Information Education and Communication activities and media must be harnessed in creating awareness and knowledge about vaccines and vaccine preventable diseases. Hence if steps were taken to ensure good education to the girl child and knowledge about vaccination integrated into the antenatal care of mothers, the vaccination coverage will be near complete and the goals of eradication of diseases like polio may be achieved. 


\section{CONCLUSION}

A significant number of mothers in rural areas were unaware about the vaccination and its implications. Even in the urban areas we found significant lacunae in the KAP of mothers towards childhood vaccination. These are the problems which need to be addressed so as to achieve vaccination coverage of $100 \%$. Health care workers at the grass root level must be trained and through them the importance of childhood vaccination disseminated to all rural areas. In the urban areas also, centralization of vaccination facilities in certain major hospitals, will ensure vaccine safety and good vaccination coverage.

\section{REFERENCES}

1. Pandey RP and Yazbeck AS. What's in a country average? Wealth, Gender and Regional Inequalities. Soc Sci Med 2003; 57(11):2075-2088.

2. Global immunization data. http://www.who.int/immunization monitoring/Global_Immunization_Data.pdf as accessed on 241-2012.
3. Weekly Epidemiological Record No.46, 2011, 86,509-520 http:// www.who.int/wer/2011/wer8646.pdf as accessed on 24-1-2012.

4. Nath B, Singh JV, Awasthi S, Bhushan V, Kumar V and Singh SK. KAP Study on Immunization of Children in a City of North India - A 30 Cluster Survey. Online J Health Allied Scs 2008;7(1):2.

5. Key Indicators for India from NFHS-3http://www.rchiips.org/ NFHS/pdf/India.pdf as accessed on 11-10-2012.

6. Singh M L, Badole CM and Singh MP. Immunization coverage and knowledge and practice of mother regarding immunization in rural areas. Indian J Public Health 1994;38(3):103-107.

7. Heininger $U$. An internet based survey on parental attitudes towards immunization. Vaccine 2006; 24(37-39):6351-6355.

8. Kapoor R and Vyas S. Awareness and Knowledge of mothers of under five children regardingimmunization in Ahmedabad. Healthline 2010;1(1):12-15.

9. Siddiqui N, Siddiqi AE, Nisar N and Khan A. Mothers knowledge about EPI and its relation with age -appropriate vaccination of infants in peri-urban Karachi. J Pak Med Assoc 2010; 60(11):940944.

10. Hamid S, Andrabi SAH, Fazli A and Jabeen R. Immunization of children in a rural area of North Kashmir India: a KAP study. Online J Health Allied Scs.2012; 11(1):10.

11. Manjunath $U$ and Pareek RP. Maternal knowledge and perceptions about the routine immunization programme--a study in a semi urban area in Rajasthan. Indian J Med Sci 2003; 57(4):158-163.

\footnotetext{
Authors Contribution:

SM - Concept and design, analysis and interpretation, manuscript preparation, revision of the manuscript and literature search; AS and PR - data collection, preparation of manuscript; DM - revision of the manuscript and literature search; BA - manuscript preparation, revision of the manuscript and literature search; MK - revision of the manuscript and literature search.
}

Source of Support: ICMR-STS Project, Conflict of Interest: None declared. 